\title{
Fermented Saccharina japonica (Phaeophyta) improves neuritogenic activity and TMT-induced cognitive deficits in rats
}

\author{
Hyun-Jung Park ${ }^{1,2}$, Mi-Sook Lee ${ }^{1}$, Hyun Soo Shim ${ }^{1}$, Gyeong-Ran Lee ${ }^{1}$, Sun Yong Chung ${ }^{1}$, \\ Young Mi Kang ${ }^{3}$, Bae-Jin Lee ${ }^{3}$, Yong Bae Seo ${ }^{3}$, Kyung Soo Kim ${ }^{4}$ and Insop Shim ${ }^{1, *}$ \\ ${ }^{1}$ Department of Science in Korean Medicine, Graduate School, College of Korean Medicine, Kyung Hee University, Seoul \\ 02453, Korea \\ ${ }^{2}$ Department of Psychology and Center for Neuroscience, Brigham Young University, Provo, UT 84602, USA \\ ${ }^{3}$ Marine Bioprocess Co., Ltd., Busan 46046, Korea \\ ${ }^{4}$ Department of Integrative Medicine and the Research Center of Behavioral Medicine, College of Medicine, The Catholic \\ University of Korea, Seoul 06591, Korea
}

Marine organisms are frequently used to be harmful and have lower side effects than synthetic drugs. The cognitive improving efficacy of gamma aminobutyric acid-enriched fermented Saccharina japonica (FSJ) on the memory deficient rats, which were induced by trimethyltin chloride (TMT), was investigated by assessing the Morris water maze test and by performing choline acetyltransferase (ChAT), cAMP response element binding protein (CREB), and brain derived neurotrophic factor (BDNF) immunohistochemistry. The neurite outgrowth of Neuro2a cells was assessed in order to examine the underlying mechanisms of the memory enhancing effects of FSJ. Treatment with FSJ tended to shorten the latency to find the platform in the acquisition test of the Morris water maze at the second and fourth day compared to the control group. In the probe trial, the FSJ treated group increased time spent in the target quadrant, compared to that of the control group. Consistent with the behavioral data, these treatments recovered the loss of ChAT, CREB, and BDNF immunepositive neurons in the hippocampus produced by TMT. Treatment with FSJ markedly stimulated neurite outgrowth of the Neuro2a cells as compared to that of the controls. These findings demonstrate that FSJ may be useful for improving the cognitive function via regulation of neurotrophic marker enzyme activity.

Key Words: brain derived neurotrophic factor; cAMP response element binding protein; gamma aminobutyric acid; Morris water maze; Saccharina japonica; trimethyltin

\section{INTRODUCTION}

In the past few years, many new drugs have been developed from natural or marine organisms. Also, there is an increasing trend of using alternative therapies including fermented products. During fermentation of Saccharina japonica (previously known as Laminaria japonica), the degradation products, amino acids and peptides have significant effect on the biochemical characteristics of fermented S. japonica (FSJ). Several studies reported that marine plants produce biological activities. For example, marine organisms including sea oyster might be useful for the prevention and treatment of liver diseases by inhibiting an oxidation process (Watanabe et al. 2012).
(1) $\$$ This is an Open Access article distributed under the terms of the Creative Commons Attribution Non-Commercial License (http://creativecommons.org/licenses/by-nc/3.0/) which permits unrestricted non-commercial use, distribution, and reproduction in any medium, provided the original work is properly cited.
Received August 25, 2015, Accepted November 10, 2015

*Corresponding Author

E-mail: ishim@khu.ac.kr

Tel: +82-2-961-0698, Fax: +82-2-963-2175 
Many constituents of laminaria have been used for medical treatments. One of the polysaccharide constituent of laminaria, laminarin, has antilipemic and anticoagulant functions. It has been known that the other constituents, histamine and lamine have the hypotensive effects (Walsh et al. 1982). Another constituent of laminaria, algin (sodium alginate) has anti-diarrhea and soothing effects (Gao et al. 2013, Liu and Zhao 2013). Also alginatecontaining kelp has been used for managing radioactive intoxication (Harikrishnan et al. 2011).

Gamma aminobutyric acid (GABA) is biosynthesized by animals, plants, and microorganisms via the $\alpha$-decarboxylation of glutamic acid by a glutamate decarboxylase (Ueno 2000). A variety of traditional foods produced during process of microbial fermentation contain GABA. Several studies have reported that GABA is produced by most lactic acid bacteria, including $L a c$ tobacillus brevis, Lactobacillus paracasei, Lactobacillus buchneri, and Lactobacillus sakei B2-16 (Yokoyama et al. 2002, Choi et al. 2006, Kim et al. 2009, Kook et al. 2010). Glutamate is a major substance for GABA production and is especially abundant in foods such as sea tangle, cheese, soybeans, rice bran, and mushrooms (Kook et al. 2010, Lee et al. 2010a). In our previous study, it was shown that GABA-producing L. brevis BJ20 was isolated from Jotgal, a Korean traditional fermented food and was capable of completing conversion of $L$. japonica glutamic acid into GABA (Lee et al. 2010a), and GABA-enriched FSJ has been demonstrated to produce a number of biological effects such as hepatotoxicity improvement and anti-oxidant activity (Lee et al. 2010a, 2010b).

Trimethyltin chloride (TMT) is known as a classic neurotoxicant which can cause serious neuronal degeneration diseases. Exposure of the human population to many chemicals has generated concern about the potential neurotoxicity of new and exciting chemicals (Kaur et al. 2013). Our previous studies already proved through experimental observations that TMT-induced neurodegenerative processes support the efficiency and sensitivity of this model for providing insights into the mechanisms of neuro-degeneration (Park et al. 2011, 2012b). TMT-induced neuronal damage particularly in the hippocampal formation resulted in behavioral alterations such as hyperactivity, impairment of learning and memory (Koczyk 1996, Guo et al. 2004), epilepsy and spontaneous seizures (Geloso et al. 2011). TMT also procures cellular oxidative stress which leads to apoptotic death (Gunasekar et al. 2001, Jenkins and Barone 2004, Mundy and Freudenrich 2006). Also it has been shown that TMT-induced deficits with learning and memory may be mediated by the central cholinergic systems or neurotrophic factors such as brain derived neurotrophic factor (BDNF) and cAMP response element binding protein (CREB) (Park et al. 2012b).

The present study was to evaluate the memory improving effect of FSJ on TMT-induced learning and memory deficits and to examine the mechanism underlying these protective effects in rats. Rats were tested on a Morris water maze for spatial learning and memory and then the parameters such as expression of choline acetyltransferase (ChAT), CREB, and BDNF in the hippocampus and the neurite outgrowth of Neuro2a cells were analyzed.

\section{MATERIALS AND METHODS}

\section{Animals and the experimental procedure}

Male Sprague-Dawley rats weighting 250-280 g each were purchased from Samtaco Animal Corp. (Osan, Korea). The animals were acclimatized for at least 7 days prior to the experiment. The animals were housed in individual cages under light-controlled conditions (12: 12-h light : dark cycle) and at $23^{\circ} \mathrm{C}$ room temperature. Food and water were made available ad libitum. All the experiments were approved by the Kyung Hee University institutional animal care and use committee. Also, this experimental protocol was approved by an Institutional Review Committee for the use of Human or Animal Subjects and the procedures were in compliance with the Declaration of Helsinki for human subjects, or the National Institutes of Health Guide for Care and Use of Laboratory Animals (Publication No. 85-23, revised 1985), the UK Animals Scientific Procedures Act 1986 or the European Communities Council Directive of 24 November 1986 (86/609/EEC).

The rats were injected intraperitoneally with TMT (8.0 mg $\mathrm{kg}^{-1}$, body weight) dissolved in $0.9 \%$ saline and then they were returned to their home cages. From the 15th day after the injection of the drug (for 21 days, treatment of FSJ 50, 100, or $200 \mathrm{mg} \mathrm{kg}^{-1}$, per oral was given), the water maze test was performed for 5 days.

\section{Preparation of FSJ}

FSJ was prepared as described by Kang et al. (2012). For the production of GABA-enriched preparations, S. japonica were added to water at a ratio of $1: 15(\mathrm{w} / \mathrm{v})$ and $3 \%$ yeast extract and $1 \%$ glucose were then added to the mixture, each based on the amount of yeast extract and L. japonica required to aid in the fermentation process. 
After autoclaving at $121^{\circ} \mathrm{C}$ for $30 \mathrm{~min}, \mathrm{FSJ}$ was filtered and Lactobacillus brevis BJ20 (accession No. the Korean Collection for Type Culture [KCTC] 11377BP) culture broth was mixed to the fermented sample at a concentration of $5 \%(\mathrm{v} / \mathrm{v})$, which was well mixed and then incubated at $37^{\circ} \mathrm{C}$. The GABA content in the culture broth was measured as follows. A 1-mL sample was taken and diluted 20 -fold using $0.02 \mathrm{~N} \mathrm{HCl}$. The dilution solution $(2 \mathrm{~mL}$ ) was filtered through a $0.2-\mu \mathrm{m}$ membrane filter (dismic- $25 \mathrm{cs}$; Toyo Roshi Kaisha, Tokyo, Japan). The GABA and glutamate in the filtered sample $(20 \mu \mathrm{L})$ were measured using amino acid analyzer (AAA L-8900; Hitachi High-Technologied Co., Tokyo, Japan) with a flow rate of $0.3 \mathrm{~mL} \mathrm{~min}^{-1}$. FSJ contained $6.29 \%(\mathrm{w} / \mathrm{w})$ glutamic acid and GABA was not detected before fermentation of FSJ. However, GABA content $(5.56 \%$, w/w dry weight) was dramatically increased during fermentation with $L$. brevis. Phophoserine, aspartic acid, threonine, serine, and glycine were also increased after fermentation. These results were in agreement with our previous report (Lee et al. 2010a).

\section{Morris water maze test}

The swimming pool of the Morris water maze was a circular water tank $200 \mathrm{~cm}$ in diameter and $35 \mathrm{~cm}$ deep. It was filled $21 \mathrm{~cm}$ height with opaque water at $23 \pm 2^{\circ} \mathrm{C}$. A platform $15 \mathrm{~cm}$ in diameter and $20 \mathrm{~cm}$ in height was placed inside the tank with its top surface being $1.5 \mathrm{~cm}$ below the surface of the water. Four different visual cues were mounted on the four directions of the walls. A CCD camera was equipped with a computer for the behavior recording. For the acquisition test, each rat was trained three trials a day. The rat had to find the hidden platform for $180 \mathrm{~s}$, and the escape latency was used as an index of performance in the task. For 4 consecutive days, rats were tested with three acquisition trials. On the 5th day, they received a $1 \mathrm{~min}$ probe trial in which the platform was removed from the pool. The performance of the test animals in each water maze trial was assessed by a personal computer for the behavioral analysis using a S-mart Program (PanLab, Barcelona, Spain).

\section{Immunohistochemistry}

For immunohistochemical examination, rats were anesthetized with sodium pentobarbital $\left(100 \mathrm{mg} \mathrm{kg}^{-1}\right.$, intraperitoneally) and then perfused transcardially with heparinized phosphate-buffered saline (PBS; pH 7.4) for $30 \mathrm{~s}$ followed by $4 \%$ paraformaldehyde in $0.1 \mathrm{M}$ phosphate buffer ( $\mathrm{pH}$ 7.4) for 10-15 min. The brains were post- fixed in the same fixative overnight, cryoprotected in 30\% sucrose solution in PBS, embedded and serially sectioned on a cryostat (Leica Microsystem Co., Ltd., Wetzlar, Germany) at $30 \mu \mathrm{m}$ thickness in the coronal plane and they were collected in PBS. The primary antibodies against the following specific antigen were used: cAMP response element-binding protein (rabbit polyclonal CREB, 1:500; Cell Signaling, Danvers, MA, USA) and BDNF responsive element binding protein (rabbit polyclonal BDNF, 1:500; Santa Cruz Biotechnology, Santa Cruz, CA, USA) and ChAT (sheep polyclonal ChAT, $1: 2,000$; Chemicon, Temecula, CA, USA). The primary antibodies were prepared and diluted in $0.3 \%$ PBST, $2 \%$ blocking serum and $0.001 \%$ keyhole limpet hemocyanin (Sigma, St. Louis, MO, USA). The sections were incubated in the primary antiserum for $72 \mathrm{~h}$ at $4^{\circ} \mathrm{C}$. After three more rinses in PBST, the sections were placed in Vectastain Elite ABC reagent (Vector Laboratories, Burlingame, CA, USA) for $2 \mathrm{~h}$ at room temperature. Following a further rinsing in PBS, the tissue was developed using diaminobenzadine (Sigma) as the chromogen. The images were captured using a DP2-BSW imaging system (Olympus, San Diego, CA, USA) and they were processed using Adobe Photoshop. For counting the cells that were positive for CREB, BDNF, and ChAT, the $200 \times 200 \mathrm{~mm}$ rectangle grid was placed on CAl and CA3 in the hippocampus according to the method of Paxinos et al. (1985).

\section{Cell culture}

The Neuro2a cells were kindly provided by Korea Centers for Disease Control and Prevention, Dr. Kim from the Republic of Korea. The cells were grown in Dulbecco's modified minimum essential medium (DMEM) supplemented with $10 \%(\mathrm{v} / \mathrm{v})$ heat-inactivated fetal bovine serum under a $5 \% \mathrm{CO}_{2} / 95 \%$ humidified air at $37^{\circ} \mathrm{C}$, and the cells were sub-cultured every 3-4 days. The medium was changed every 2-3 days.

\section{Evaluation of neurite outgrowth}

The Neuro2a cells were plated onto 35-mm plastic culture dishes coated with collagen (type I from calf skin; Sigma) at a density of $5 \times 10^{4}$ cells well $^{-1}$ and then they were incubated for $24 \mathrm{~h}$ at $37^{\circ} \mathrm{C}$ in $5 \% \mathrm{CO}_{2}$. After $24 \mathrm{~h}$, the culture medium was changed by serum-free DMEM medium. The cells were added with different concentrations of FSJ diluted in sterile PBS at pH 7.4 to attain the desired FSJ concentrations of 10 and $50 \mu \mathrm{g} \mathrm{mL}{ }^{-1}$. After $72 \mathrm{~h}$, the cells were rinsed with PBS and then $1 \mathrm{~mL}$ of $0.1 \%$ glutaral- 


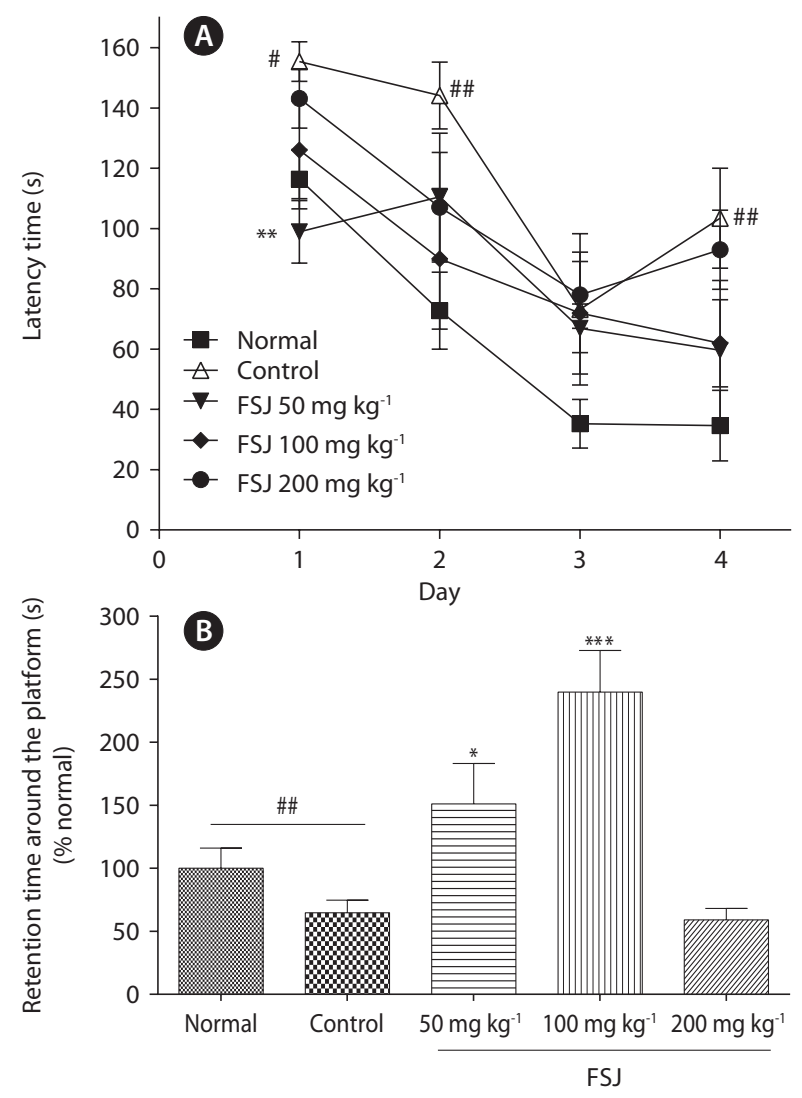

Fig. 1. (A) The latency of escape onto the hidden platform during the Morris water maze. The task was performed with 3 trials per day during 4 days for the acquisition test. Data were plotted as mean \pm standard error of the mean (SEM). FSJ, fermented Saccharina japonica. ${ }^{*} p<0.05,{ }^{* \# *} p<0.01$ vs. normal group and ${ }^{* *} p<0.01$ vs. control group, respectively. (B) Probe test was performed on the 5th day for $60 \mathrm{~s}$. Data were plotted as \pm SEM. ${ }^{\# \#} \mathrm{p}<0.01 \mathrm{vs}$. normal group and ${ }^{*} p<0.05,{ }^{* * *} p<0.001$ vs. control group, respectively.

dehyde solution was added and then the cells were incubated for $30 \mathrm{~min}$ in room temperature. The length of the longest neurite of the individual cells was measured by phase-contrast microscope image analyze system (Model DC-300F; Leica Microsystem Co., Ltd.) that was attached to a phase-contrast microscope ( $\times 200$ magnification) and by using software (Qwin Plus 271; Leica Microsystem Imaging Solutions Co., Ltd., Cambridge, UK).

\section{Statistical analysis}

The behavioral and immunohistochemical data were statistically analyzed by one-way or two-way ANOVA with repeated measures. Tukey's post hoc test was carried out to identify the differences among the means of groups (SPSS ver. 15.0; SPSS Inc., Chicago, IL, USA). The results are expressed as means \pm standard error of mean (SEM). p-values less than 0.05 were considered statistically significant.

\section{RESULTS}

\section{Effect of FSJ on the performance of the water maze task}

Effects of FSJ (50, 100, and $\left.200 \mathrm{mg} \mathrm{kg}^{-1}\right)$ on learning and memory were evaluated using the Morris water maze test, in which learning process was tested during acquisition trials and memory aspect was tested in probe trials.

The escape latency of the control group was longer than that of the normal group during all sessions, and Fig. 1A shows the mean time latencies in reaching the hidden platform in the acquisition test of the Morris water maze for all the groups for 4 days. The control group showed a worse performance than did the normal group $(\mathrm{p}<0.05$ at the day 1 and $\mathrm{p}<0.01$ at the days 2 and 4). There were significant main effects, and treatment with FSJ (50 mg $\mathrm{kg}^{-1}$ ) had a significant interaction effect on the escape latency of control group from the first day $(\mathrm{p}<0.01)$.

In the probe test, FSJ treatment showed an increase in time spent around the platform compared to that of the control group (50 and $100 \mathrm{mg} \mathrm{kg}^{-1}, \mathrm{p}<0.05$ and $\mathrm{p}<0.001$, respectively), reflecting enhancing effect of memory function by FSJ.

\section{CREB immunoreactive neurons of the hippo- campus}

The expression of CREB immunoreactive cells per section from the different subregions of the hippocampus is shown in Fig. 2A and B. Statistical analysis indicated that the CREB immunoreactivity in the hippocampus of the control group was significantly lower than that of the normal group. In particular, significant differences were observed in the hippocampal CA1 $(\mathrm{p}<0.05)$ and CA3 ( $\mathrm{p}$ $<0.001$ ). The CREB reactivity in the FSJ $50 \mathrm{mg} \mathrm{kg}^{-1}$ group was higher than that of the control group $(\mathrm{p}<0.05)$ in the CA1, where, the number of CREB positive neurons in the FSJ $50 \mathrm{mg} \mathrm{kg}^{-1}$ group was significantly increased by $119.7 \%$ compared to that of the control group ( $p<0.05)$ (Fig. 2).

\section{BDNF immunoreactive neurons of the hippo- campus}

The expression of the evaluations of the BDNF immune-positive neurons per section from the different 
B

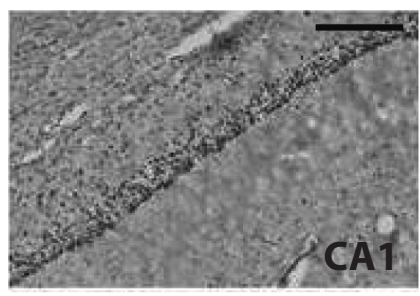

Normal

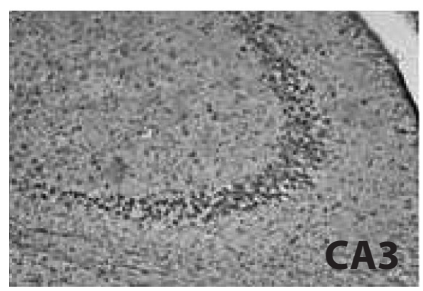

Normal

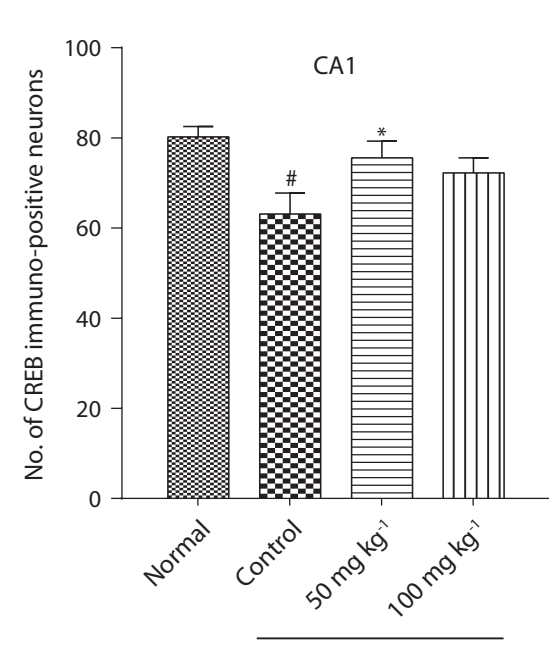

FSJ

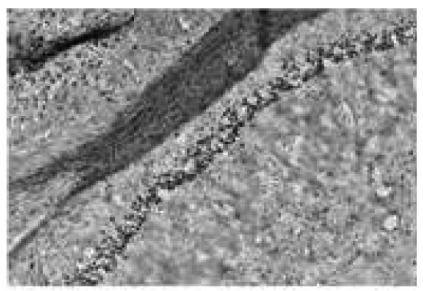

Control

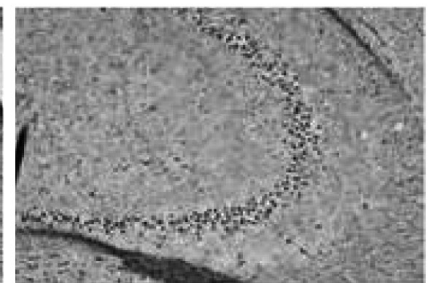

Control

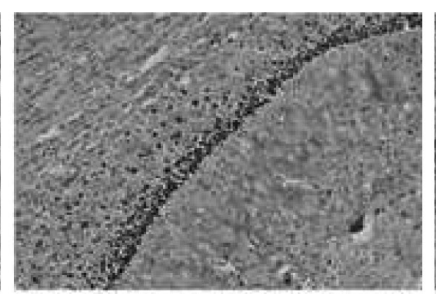

FSJ $50 \mathrm{mg} \mathrm{kg}^{-1}$

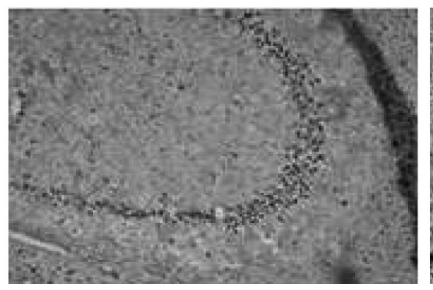

FSJ $50 \mathrm{mg} \mathrm{kg}^{-1}$

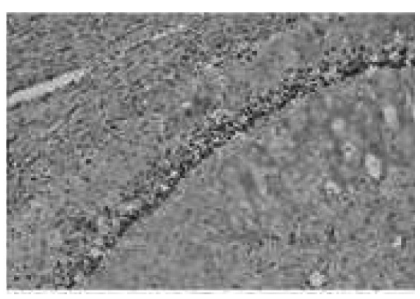

FSJ $100 \mathrm{mg} \mathrm{kg}^{-1}$

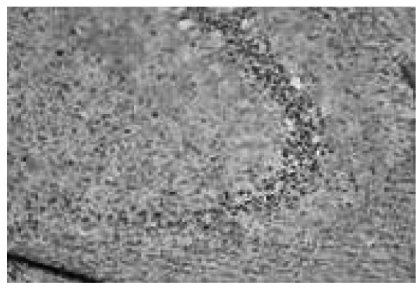

FSJ $100 \mathrm{mg} \mathrm{kg}^{-1}$

Fig. 2. (A) The expression of CAMP responsive element binding protein (CREB) immunostained nuclei in different hippocampal CA1 and CA3 of the experimental groups. Each value represents the mean \pm standard error of the mean. ${ }^{*} p<0.05,{ }^{* \# *} p<0.001$ vs. normal group and ${ }^{*} p<0.05$ vs. control group, respectively. (B) Representative photographs showing the distribution of CREB-immunoreactive cells in the hippocampus of normal group, control group, fermented Saccharina japonica (FSJ) $50 \mathrm{mg} \mathrm{kg}^{-1}$ group, and FSJ $100 \mathrm{mg} \mathrm{kg}^{-1}$. Sections were cut coronally at 30 um. Scale bar represents: $200 \mu \mathrm{m}$.

hippocampal formations is shown in Fig. 3A and B. Statistical analysis indicated that the BDNF immunoreactivity in the hippocampus of the control group was significantly lower than that of the normal group, in the hippocampal CA1 $(p<0.05)$ and CA3 $(p<0.01)$. The BDNF reactivity in the FSJ $50 \mathrm{mg} \mathrm{kg}^{-1}$ group was higher than that of the control group $(\mathrm{p}<0.01)$ in both CA1 and CA3. In the hippocampal CA3, the number of BDNF positive neurons in the FSJ $50 \mathrm{mg} \mathrm{kg}^{-1}$ group was significantly increased by $404.5 \%$ compared to that of the control group $(\mathrm{p}<0.01)$ (Fig. 3).

\section{ChAT immunoreactive neurons of the hippo- campus}

The expression of the ChAT immunoreactive neurons per section from the different hippocampus is shown in Fig. 4A and B. Statistical analysis indicated that the ChAT activity in the hippocampus of the control group was significantly lower than that of the normal group-in the hippocampal CA1 $(p<0.01)$ where the number of ChAT positive neurons in the FSJ $100 \mathrm{mg} \mathrm{kg}^{-1}$ group was significantly increased by $280.0 \%$ compared to that of the control group ( $<$ 0.01) (Fig. 4). 
A

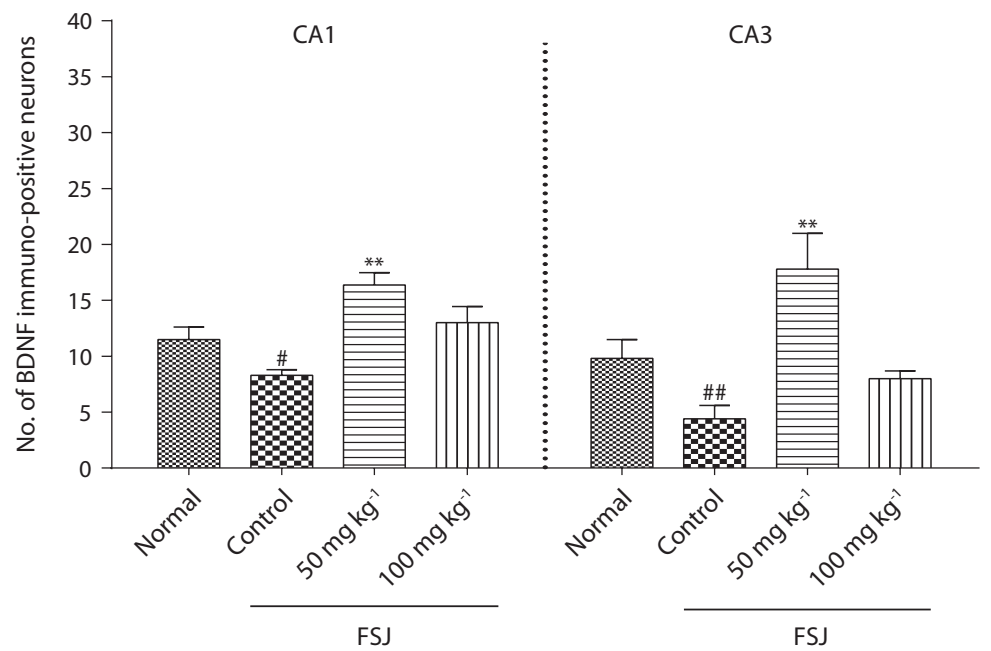

B

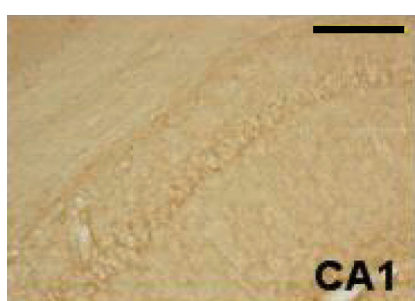

Normal

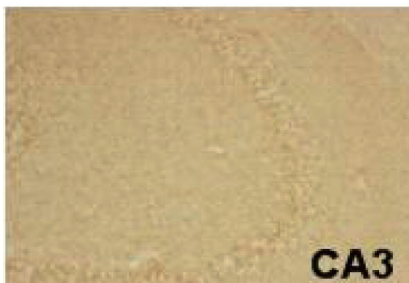

Normal

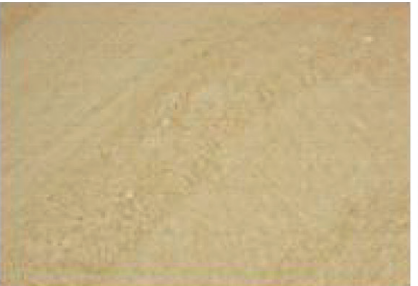

Control

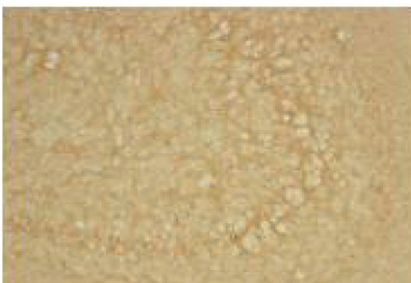

Control

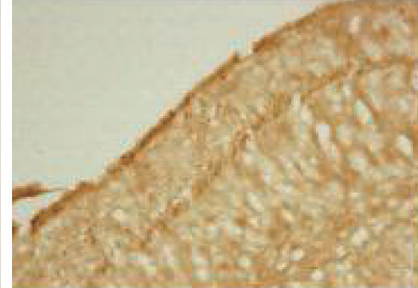

FSJ $50 \mathrm{mg} \mathrm{kg}^{-1}$

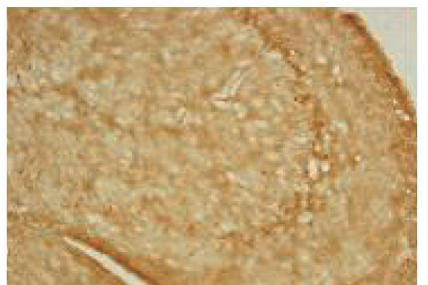

FSJ $50 \mathrm{mg} \mathrm{kg}^{-1}$

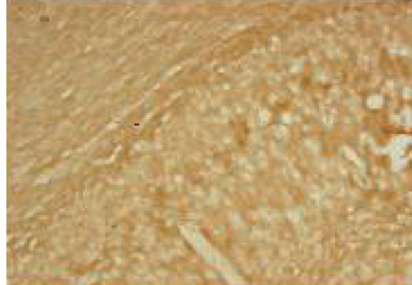

FSJ $100 \mathrm{mg} \mathrm{kg}^{-1}$

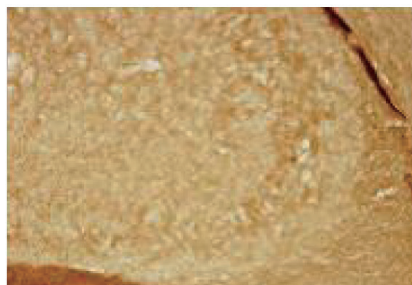

FSJ $100 \mathrm{mg} \mathrm{kg}^{-1}$

Fig. 3. (A) The expression of brain derived neurotrophic factor (BDNF) immunoreactive neurons in different hippocampal CA1 and CA3 of the experimental groups. Data were plotted as represents the mean \pm standard error of the mean. ${ }^{*} p<0.05,{ }^{* *} p<0.01$ vs. normal group and ${ }^{* *} p<0.01$ vs. control group, respectively. (B) Representative photographs showing the distribution of BDNF-immunoreactive cells in the hippocampus of normal group, control group, fermented Saccharina japonica (FSJ) $50 \mathrm{mg} \mathrm{kg}^{-1}$ group, and FSJ $100 \mathrm{mg} \mathrm{kg}^{-1}$. Sections were cut coronally at $30 \mu \mathrm{m}$. Scale bar represents: $200 \mu \mathrm{m}$. 
A

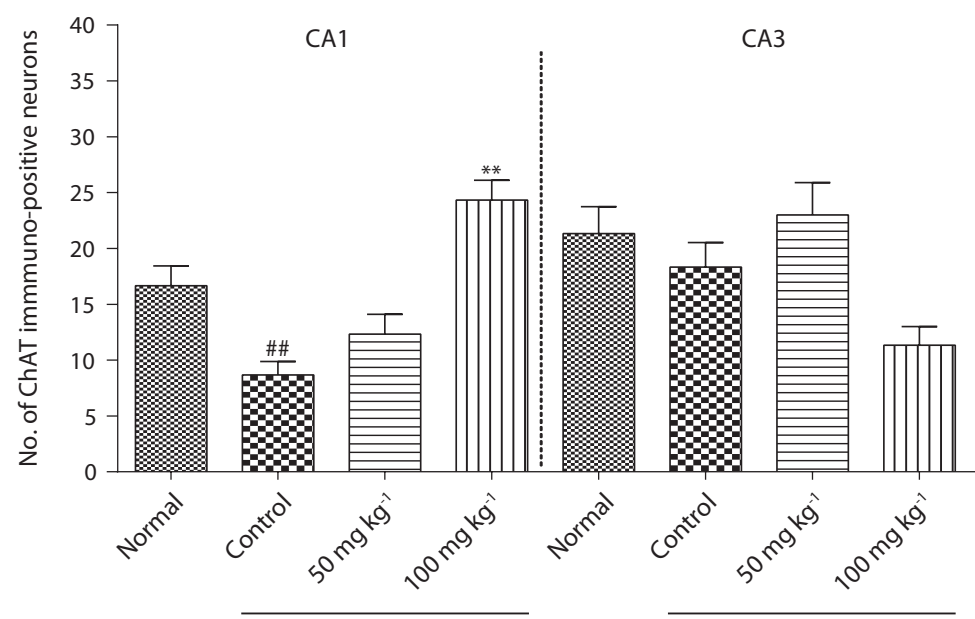

FSJ

FSJ

B

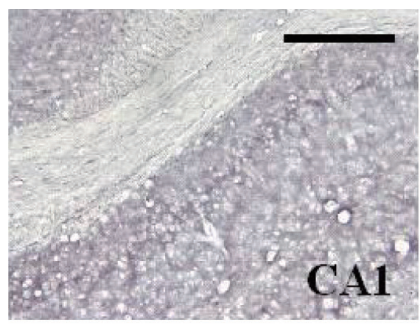

Normal

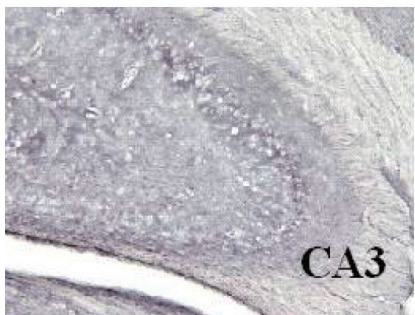

Normal

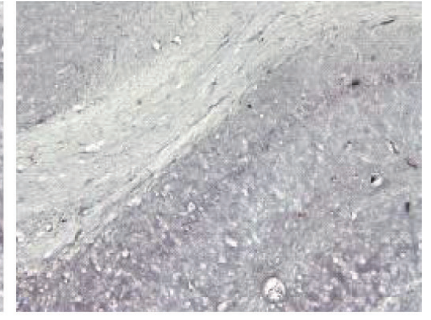

Control

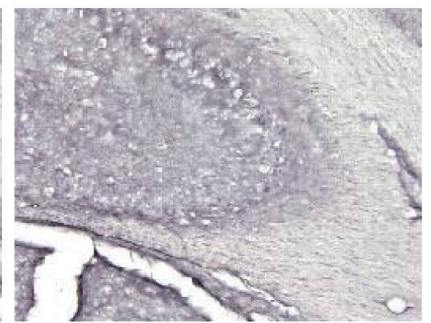

Control

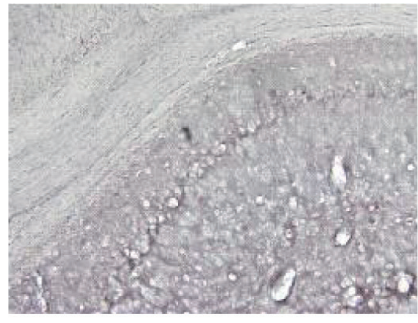

FSJ $50 \mathrm{mg} \mathrm{kg}^{-1}$

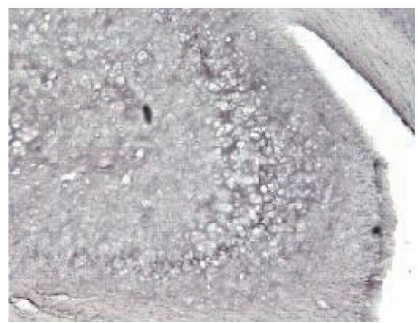

FSJ $50 \mathrm{mg} \mathrm{kg}^{-1}$

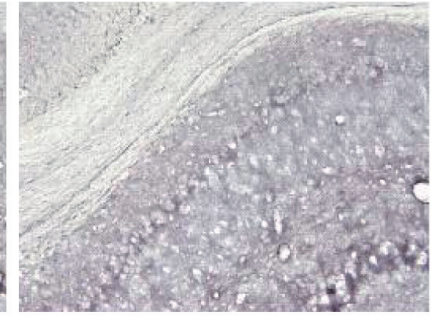

FSJ $100 \mathrm{mg} \mathrm{kg}^{-1}$

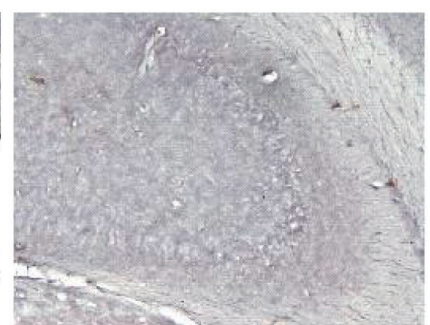

FSJ $100 \mathrm{mg} \mathrm{kg}^{-1}$

Fig. 4. (A) The expression of choline acetyltransferase (ChAT) immunoreactive neurons in different hippocampal CA1 and CA3 of the experimental groups. Data were plotted as the mean \pm standard error of the mean. ${ }^{\# \#} p<0.01$ vs. normal group and ${ }^{* *} p<0.01$ vs. control group, respectively. (B) Representative photographs showing the distribution of ChAT-immunoreactive cells in the hippocampus of normal group, control group, fermented Saccharina japonica (FSJ) $50 \mathrm{mg} \mathrm{kg}^{-1}$ group, and FSJ $100 \mathrm{mg} \mathrm{kg}^{-1}$. Sections were cut coronally at $30 \mu \mathrm{m}$. Scale bar represents: $200 \mu \mathrm{m}$. 
A

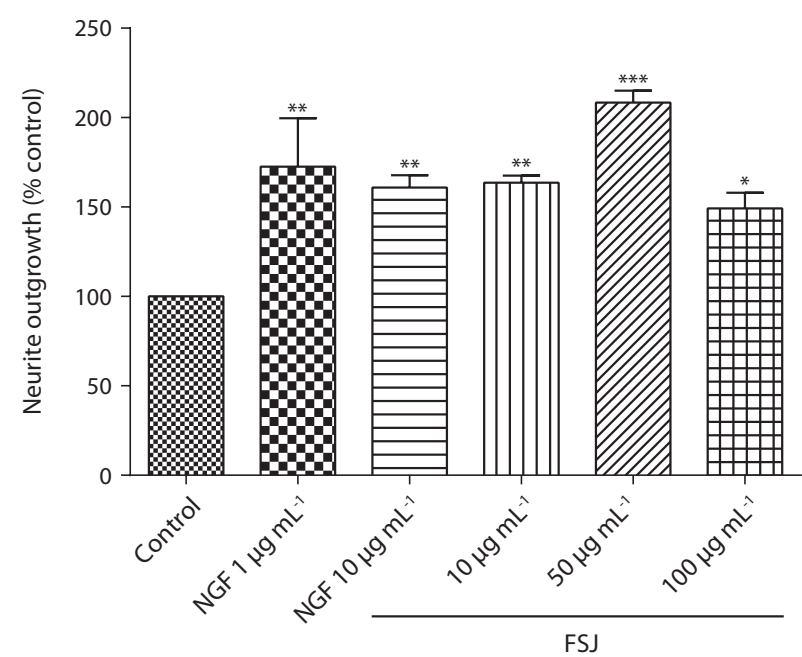

B

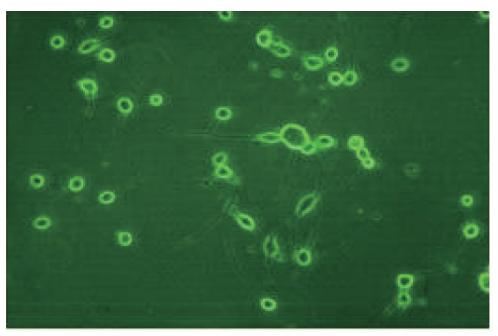

Control

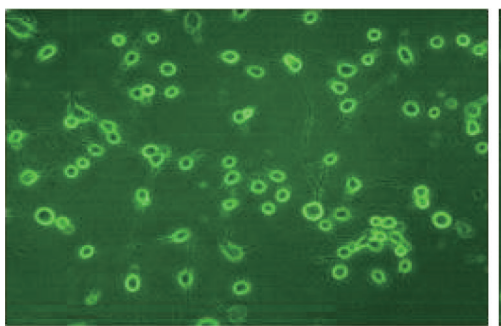

FSJ $10 \mu \mathrm{g} \mathrm{mL}^{-1}$

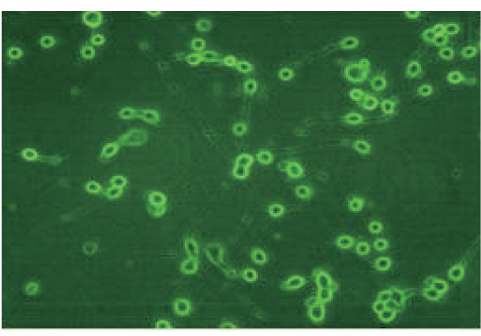

$\mathrm{NGF} 1 \mu \mathrm{g} \mathrm{mL}^{-1}$

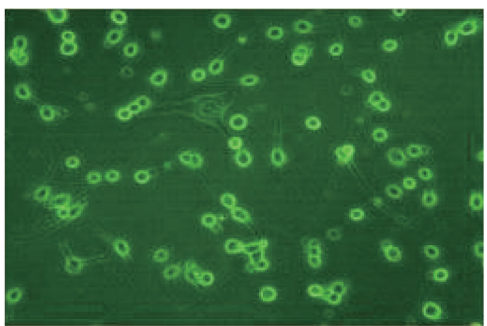

FSJ $50 \mu \mathrm{g} \mathrm{mL}^{-1}$

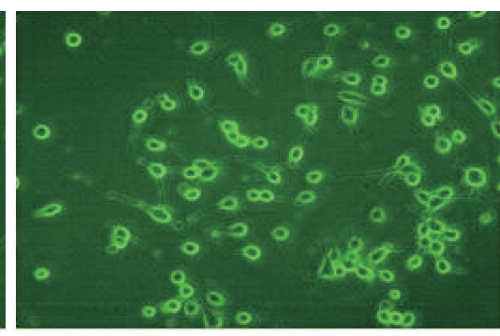

NGF $10 \mu \mathrm{gL}^{-1}$

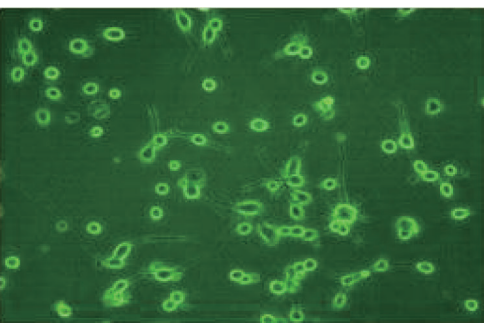

FSJ $100 \mu \mathrm{gL}^{-1}$

Fig. 5. (A) Neurite outgrowth induced by treatment with the fermented Saccharina japonica (FSJ) water extract powder on Neuro2a cells. Data were plotted as the mean \pm standard error of the mean of the length of the longest neurite of the individual cells $(n=50)$ in each group. Separate measure of one-way ANOVA of the length of neurite. ${ }^{*} p<0.05,{ }^{* *} p<0.01,{ }^{* * *} p<0.001$ vs. control (vehicle). (B) Phase-contrast photomicrographs of FSJ extract powder and nerve growth factor (NGF)-induced neurites.

\section{Neuritogenesis with FSJ extract}

The neuritogenic effect of the FSJ water extract powder in the Neuro2a cells is shown in Fig. 5. Neurite outgrowth in the Neuro2a cells was significantly increased with treatment of FSJ. The higher doses of FSJ were given to the cells, the greater the increases of neurite outgrowth were observed $(\mathrm{p}<0.01$ and $\mathrm{p}<0.001$ in the 10 and $50 \mu \mathrm{g}$ $\mathrm{mL}^{-1}$ of FSJ-treated group, respectively). Also, cells treated with nerve growth factor (NGF; $1.0 \mu \mathrm{g} \mathrm{mL}^{-1}$ ) showed significantly increased neurite outgrowth $(p<0.01)$. Fig. 5B shows the morphology of the Neuro2a cells with neurite outgrowth at $24 \mathrm{~h}$ of treatment with NGF $\left(1 \mu \mathrm{g} \mathrm{mL}^{-1}\right)$, FSJ extract (10 and $50 \mu \mathrm{g} \mathrm{mL}^{-1}$ ), and vehicle (Fig. 5).

\section{DISCUSSION}

The present results demonstrated that TMT injections produced severe deficits in the rats' performances in a Morris water maze along with signs of neuronal degeneration, including decreased cholinergic neurons and CREB 
activity in the hippocampus. Repeated treatment with FSJ prevented the TMT-induced learning and memory impairments as shown in the water maze test and it had a neuroprotective effect against the TMT-induced decrease in CREB and BDNF positive neurons. Also, FSJ stimulated transcription and neurite outgrowth of the $\mathrm{PC} 12 \mathrm{~h}$ cells (Fortemps et al. 1978, Brown et al. 1979, Chang and Dyer 1983a, 1983b, 1985, Chang et al. 1983a, 1983b, Balaban et al. 1988, Koczyk 1996).

TMT induced profound behavioral and cognitive deficits in animals (Koczyk 1996, Ishida et al. 1997). Our previous studies already reported that intoxication with TMT-induced deficits in learning and memory (Park et al. 2012a, 2012b). Other studies proved the loss of learning and memory in TMT-intoxicated rats (Swartzwelder et al. 1982, Alessandri et al. 1994). The deficit in spatial learning produced by TMT in the current study is consistent with the previous studies of spatial learning impairments (Walsh et al. 1982, Zhao et al. 1982, Hagan et al. 1988, Earley et al. 1992, Alessandri et al. 1994, Woodruff et al. 1994, Koczyk et al. 1996). However, this current study proved that spatial memory in the FSJ groups was preserved during the training days compared to that of the control group. Also, the data of the spatial probe trial demonstrated that FSJ protects against the TMT-induced definite cognitive impairment, especially with regards to long-term memory. And, repeated FSJ administration proved beneficial in improving associative learning and memory processes as assessed by the Morris water maze test. Treatment with FSJ extract produced increased behavioral effects, but was without effects on it in the present study. It is not clear why this high dosage did not produce any behavioral effects. These U-shape or bidirectional patterns of dosage have been frequently observed from in vivo studies using natural products. According to analysis of ingredients, S. japonica contains approximately $55 \mathrm{mg}$ of GABA $\mathrm{g}^{-1}$. Therefore $11 \mathrm{mg}$ of GABA was injected to $200 \mathrm{mg} \mathrm{kg}^{-1}$ dosage group. GABA is a potent inhibitory neurotransmitter in the central nervous system and this amount of GABA may inhibit behavioral effects. The other reason may be due to a toxic effect from overdose of natural extracts.

The activation of CREB was known to be associated with a neuronal protective effect such as a defense mechanism. CREB is important for activating the transcription of genes controlled by the cAMP-response element, and many of these genes may be involved in neuronal growth and plasticity and they may may play a significant role in neuronal survival (Sala et al. 2000, Lonze and Ginty 2002). Several studies have shown that disruption of the CREB gene leads to neuronal degeneration (Bourtchuladze et al. 1994, Sala et al. 2000, Lonze and Ginty 2002, Mantamadiotis et al. 2002). CREB is also known to be a key molecular marker of long term potentiation and memory consolidation. Genetic and pharmacological studies have provided strong evidence that the CREB signaling pathway is necessary for learning and memory across species (Kogan et al. 1997, Jackson and Ramaswami 2003). The present study proved that the levels of CREB in the hippocampus were significantly different among the groups (Park et al. $2012 a, 2012 b$ ). The present study demonstrated that the TMT treated group showed a reduction of approximately $40 \%$ of the CREB activity. Thus, we may draw a conclusion that the CREB loss after TMT exposure might be at least partially responsible for the TMT-induced cell death and TMT played a role as a stressor on the CREB gene. A previous study reported the protective effect of FSJ in the Caco-2 and Raw 264.7 cell lines (Kuda et al. 2012, Küpper et al. 2013). A clinical study also proved that fermented FSJ enhanced the antioxidant defense system in a healthy population and may be useful as a functional food ingredient (Kang et al. 2012). In this study, we also found the protection of TMT-induced CREB loss in the repeatedly treated FSJ groups.

BDNF, a member of the neurotrophin family, plays a key role in neuronal survival and differentiation and synaptic plasticity (Thoenen 1995, Mizuno et al. 2000, Lipsky and Marini 2007, Lu et al. 2008). The beneficial effect on learning and memory could have been mediated by the increased synaptic plasticity (Cotman and Berchtold 2002, Farmer et al. 2004), neurotransmission and growth factor expression (Leibrock et al. 1989) that were observed in the rats. Many studies have shown that hippocampal BDNF expression was increased during process of spatial learning (Korte et al. 1995, Gooney et al. 2002), and BDNF knockout mice produced deficits in spatial learning and synaptic plasticity (Jones and Clemmons 1995, Heldt et al. 2007). Reduction in the synthesis or availability of central neurotrophic factors such as BDNF might play a critical role in the aging and degenerative processes. Also, in this study, we have focused on the role of BDNF as one of the potential mediators of these effects. In this study, there was a 204-404\% increase in the number of BDNF positive cells in the hippocampus of the FSJ $50 \mathrm{mg} \mathrm{kg}^{-1}$ treated rats, improving their learning and memory.

The rat pheochromocytoma Neuro2a cell line has been largely used as a model for studying neuronal differentiation. Neuro2a cells respond to neutrophic factors, such as NGF and fibroblast growth factor, by differentiating into sympathetic neuron-like phenotypes that are character- 
ized by neurite outgrowth and the expression of many neuron-specific proteins. In the present study, treatment with the FSJ water extract powder significantly increased neurite outgrowth in the Neuro2a cells in a dose dependent manner. These findings support the hypothesis that FSJ improves the functioning of the neurotrophic system.

In conclusion, treatment with FSJ reduced the TMTinduced learning and memory deficits as shown with the Morris water maze test, and FSJ treatment had a neuroprotective effect against a TMT-induced decrease of the BDNF, CREB, and ChAT immunoreactivity. Treatment with FSJ also significantly increased the neurite outgrowth of the PC12h cells. Thus, our findings indicate that FSJ is a good candidate for further investigations that may ultimately result in its clinical use.

\section{ACKNOWLEDGEMENTS}

This research was supported by the Korea Institute of Planning and Evaluation for Technology in Food, Agriculture, Forestry and Fisheries the National Research Foundation of Korea (NRF) funded by the Ministry of Education, Science and Technology (2011-0030091 and 2006-2005240) and the 2013 research leave program and a post-doctoral fellowship (KHU-20110693) from Kyung Hee University.

\section{REFERENCES}

Alessandri, B., FitzGerald, R. E., Schaeppi, U., Krinke, G. J. \& Classen, W. 1994. The use of an unbaited tunnel maze in neurotoxicology: I. Trimethyltin-induced brain lesions. Neurotoxicology 15:349-357.

Balaban, C. D., O’Callaghan, J. P. \& Billingsley, M. L. 1988. Trimethyltin-induced neuronal damage in the rat brain: comparative studies using silver degeneration stains, immunocytochemistry and immunoassay for neuronotypic and gliotypic proteins. Neuroscience 26:337-361.

Bourtchuladze, R., Frenguelli, B., Blendy, J., Cioffi, D., Schutz, G. \& Silva, A. J. 1994. Deficient long-term memory in mice with a targeted mutation of the cAMP-responsive element-binding protein. Cell 79:59-68.

Brown, A. W., Aldridge, W. N., Street, B. W. \& Verschoyle, R. D. 1979. The behavioral and neuropathologic sequelae of intoxication by trimethyltin compounds in the rat. Am. J. Pathol. 97:59-82.

Chang, L. W. \& Dyer, R. S. 1983a. A time-course study of trimethyltin induced neuropathology in rats. Neurobehav.
Toxicol. Teratol. 5:443-459.

Chang, L. W. \& Dyer, R. S. 1983b. Trimethyltin induced pathology in sensory neurons. Neurobehav. Toxicol. Teratol. 5:673-696.

Chang, L. W. \& Dyer, R. S. 1985. Septotemporal gradients of trimethyltin-induced hippocampal lesions. Neurobehav. Toxicol. Teratol. 7:43-49.

Chang, L. W., Tiemeyer, T. M., Wenger, G. R. \& McMillan, D. E. 1983a. Neuropathology of trimethyltin intoxication. III. Changes in the brain stem neurons. Environ. Res. 30:399-411.

Chang, L. W., Wenger, G. R., McMillan, D. E. \& Dyer, R. S. $1983 \mathrm{~b}$. Species and strain comparison of acute neurotoxic effects of trimethyltin in mice and rats. Neurobehav. Toxicol. Teratol. 5:337-350.

Choi, S. -I., Lee, J. -W., Park, S. -M., Lee, M. -Y., Ji, G. -E., Park, M. -S. \& Heo, T. -R. 2006. Improvement of $\gamma$-aminobutyric acid (GABA) production using cell entrapment of Lactobacillus brevis GABA 057. J. Microbiol. Biotechnol. 16:562-568.

Cotman, C. W. \& Berchtold, N. C. 2002. Exercise: a behavioral intervention to enhance brain health and plasticity. Trends Neurosci. 25:295-301.

Earley, B., Burke, M. \& Leonard, B. E. 1992. Behavioural, biochemical and histological effects of trimethyltin (TMT) induced brain damage in the rat. Neurochem. Int. 21:351-366.

Farmer, J., Zhao, X., van Praag, H., Wodtke, K., Gage, F. H. \& Christie, B. R. 2004. Effects of voluntary exercise on synaptic plasticity and gene expression in the dentate gyrus of adult male Sprague-Dawley rats in vivo. Neuroscience 124:71-79.

Fortemps, E., Amand, G., Bomboir, A., Lauwerys, R. \& Laterre, E. C. 1978. Trimethyltin poisoning: report of two cases. Int. Arch. Occup. Environ. Health 41:1-6.

Gao, W., Lin, T., Li, T., Yu, M., Hu, X. \& Duan, D. 2013. Sodium alginate/heparin composites on PVC surfaces inhibit the thrombosis and platelet adhesion: applications in cardiac surgery. Int. J. Clin. Exp. Med. 6:259-268.

Geloso, M. C., Corvino, V. \& Michetti, F. 2011. Trimethyltininduced hippocampal degeneration as a tool to investigate neurodegenerative processes. Neurochem. Int. 58:729-738.

Gooney, M., Shaw, K., Kelly, A., O’Mara, S. M. \& Lynch, M. A. 2002. Long-term potentiation and spatial learning are associated with increased phosphorylation of TrkB and extracellular signal-regulated kinase (ERK) in the dentate gyrus: evidence for a role for brain-derived neurotrophic factor. Behav. Neurosci. 116:455-463.

Gunasekar, P. G., Mickova, V., Kotyzova, D., Li, L., Borow- 
itz, J. L., Eybl, V. \& Isom, G. E. 2001. Role of astrocytes in trimethyltin neurotoxicity. J. Biochem. Mol. Toxicol. 15:256-262.

Guo, F. C., Kwakkel, R. P., Williams, B. A., Parmentier, H. K., Li, W. K., Yang, Z. Q. \& Verstegen, M. W. 2004. Effects of mushroom and herb polysaccharides on cellular and humoral immune responses of Eimeria tenella-infected chickens. Poult. Sci. 83:1124-1132.

Hagan, J. J., Jansen, J. H. \& Broekkamp, C. L. 1988. Selective behavioural impairment after acute intoxication with trimethyltin (TMT) in rats. Neurotoxicology 9:53-74.

Harikrishnan, R., Kim, M. -C., Kim, J. -S., Han, Y. -J., Jang, I. -S., Balasundaram, C. \& Heo, M. S. 2011. Immunomodulatory effect of sodium alginate enriched diet in kelp grouper Epinephelus brneus against Streptococcus iniae. Fish Shellfish Immunol. 30:543-549.

Heldt, S. A., Stanek, L., Chhatwal, J. P. \& Ressler, K. J. 2007. Hippocampus-specific deletion of BDNF in adult mice impairs spatial memory and extinction of aversive memories. Mol. Psychiatr. 12:656-670.

Ishida, N., Akaike, M., Tsutsumi, S., Kanai, H., Masui, A., Sadamatsu, M., Kuroda, Y., Watanabe, Y., McEwen, B. S. \& Kato, N. 1997. Trimethyltin syndrome as a hippocampal degeneration model: temporal changes and neurochemical features of seizure susceptibility and learning impairment. Neuroscience 81:1183-1191.

Jackson, T. \& Ramaswami, M. 2003. Prospects of memorymodifying drugs that target the CREB pathway. Curr. Opin. Drug Discov. Devel. 6:712-719.

Jenkins, S. M. \& Barone, S. Jr. 2004. The neurotoxicant trimethyltin induces apoptosis via caspase activation, p38 protein kinase, and oxidative stress in PC12 cells. Toxicol. Lett. 147:63-72.

Jones, J. I. \& Clemmons, D. R. 1995. Insulin-like growth factors and their binding proteins: biological actions. Endocr. Rev. 16:3-34.

Kang, Y. M., Lee, B. -J., Kim, J. I., Nam, B. -H., Cha, J. -Y., Kim, Y. -M., Ahn, C. -B., Choi, J. -S., Choi, I. S. \& Je, J. -Y. 2012. Antioxidant effects of fermented sea tangle (Laminaria japonica) by Lactobacillus brevis BJ20 in individuals with high level of $\gamma$-GT: a randomized, double-blind, and placebo-controlled clinical study. Food Chem. Toxicol. 50:1166-1169.

Kaur, S., Chhabra, R. \& Nehru, B. 2013. Ginkgo biloba extract attenuates hippocampal neuronal loss and cognitive dysfunction resulting from trimethyltin in mice. Phytomedicine 20:178-186.

Kim, J. Y., Lee, M. Y., Ji, G. E., Lee, Y. S. \& Hwang, K. T. 2009. Production of $\gamma$-aminobutyric acid in black raspberry juice during fermentation by Lactobacillus brevis
GABA100. Int. J. Food Microbiol. 130:12-16.

Koczyk, D. 1996. How does trimethyltin affect the brain: facts and hypotheses. Acta Neurobiol. Exp. (Wars.) 56:587596.

Koczyk, D., Skup, M., Zaremba, M. \& Oderfeld-Nowak, B. 1996. Trimethyltin-induced plastic neuronal changes in rat hippocampus are accompanied by astrocytic trophic activity. Acta Neurobiol. Exp. (Wars.) 56:237-241.

Kogan, J. H., Frankland, P. W., Blendy, J. A., Coblentz, J., Marowitz, Z., Schütz, G. \& Silva, A. J. 1997. Spaced training induces normal long-term memory in CREB mutant mice. Curr. Biol. 7:1-11.

Kook, M. -C., Seo, M. -J., Cheigh, C. -I., Pyun, Y. -R., Cho, S. -C. \& Park, H. 2010. Enhanced production of $\gamma$-aminobutyric acid using rice bran extracts by Lactobacillus sakei B216. J. Microbiol. Biotechnol. 20:763-766.

Korte, M., Carroll, P., Wolf, E., Brem, G., Thoenen, H. \& Bonhoeffer, T. 1995. Hippocampal long-term potentiation is impaired in mice lacking brain-derived neurotrophic factor. Proc. Natl. Acad. Sci. U. S. A. 92:8856-8860.

Kuda, T., Nakamura, S., An, C., Takahashi, H., Kimura, B. \& Nishizawa, M. 2012. Effects of holdfast of Laminaria japonica on Listeria invasion on enterocyte-like Caco2 cells and NO production of macrophage RAW 264.7 cells. Appl. Biochem. Biotechnol. 168:928-935.

Küpper, F. C., Carpenter, L. J., Leblanc, C., Toyama, C., Uchida, Y., Maskrey, B. H., Robinson, J., Verhaeghe, E. F., Malin, G., Luther, G. W. 3rd, Kroneck, P. M. H., Kloareg, B., Meyer-Klaucke, W., Muramatsu, Y., Megson, I. L., Potin, P. \& Feiters, M. C. 2013. In vivo speciation studies and antioxidant properties of bromine in Laminaria digitata reinforce the significance of iodine accumulation for kelps. J. Exp. Bot. 64:2653-2664.

Lee, B. -J., Senevirathne, M., Kim, J. -S., Kim, Y. -M., Lee, M. -S., Jeong, M. -H., Kang, Y. M., Kim, J. I., Nam, B. -H., Ahn, C. -B. \& Je, J. -Y. 2010a. Protective effect of fermented sea tangle against ethanol and carbon tetrachlorideinduced hepatic damage in Sprague-Dawley rats. Food Chem. Toxicol. 48:1123-1128.

Lee, B., Sur, B. -J., Han, J. -J., Shim, I., Her, S., Lee, H. -J. \& Hahm, D. -H. 2010b. Krill phosphatidylserine improves learning and memory in Morris water maze in aged rats. Prog. Neuropsychopharmacol. Biol. Psychiatry 34:10851093.

Leibrock, J., Lottspeich, F., Hohn, A., Hofer, M., Hengerer, B., Masiakowski, P., Thoenen, H. \& Barde, Y. -A. 1989. Molecular cloning and expression of brain-derived neurotrophic factor. Nature 341:149-152.

Lipsky, R. H. \& Marini, A. M. 2007. Brain-derived neurotrophic factor in neuronal survival and behavior-related plas- 
ticity. Ann. N. Y. Acad. Sci. 1122:130-143.

Liu, P. \& Zhao, X. 2013. Facile preparation of well-defined near-monodisperse chitosan/sodium alginate polyelectrolyte complex nanoparticles (CS/SAL NPs) via ionotropic gelification: a suitable technique for drug delivery systems. Biotechnol. J. 8:847-854.

Lonze, B. E. \& Ginty, D. D. 2002. Function and regulation of CREB family transcription factors in the nervous system. Neuron 35:605-623.

Lu, Y., Christian, K. \& Lu, B. 2008. BDNF: a key regulator for protein synthesis-dependent LTP and long-term memory? Neurobiol. Learn. Mem. 89:312-323.

Mantamadiotis, T., Lemberger, T., Bleckmann, S. C., Kern, H., Kretz, O., Villalba, A. M., Tronche, F., Kellendonk, C., Gau, D., Kapfhammer, J., Otto, C., Schmid, W. \& Schütz, G. 2002. Disruption of CREB function in brain leads to neurodegeneration. Nat. Genet. 31:47-54.

Mizuno, M., Yamada, K., Olariu, A., Nawa, H. \& Nabeshima, T. 2000. Involvement of brain-derived neurotrophic factor in spatial memory formation and maintenance in a radial arm maze test in rats. J. Neurosci. 20:7116-7121.

Mundy, W. R. \& Freudenrich, T. M. 2006. Apoptosis of cerebellar granule cells induced by organotin compounds found in drinking water: involvement of MAP kinases. Neurotoxicology 27:71-81.

Park, H. -J., Lee, S. Y., Shim, H. S., Kim, J. S., Kim, K. S. \& Shim, I. 2012a. Chronic treatment with squid phosphatidylserine activates glucose uptake and ameliorates TMTinduced cognitive deficit in rats via activation of cholinergic systems. Evid. Based Complement. Alternat. Med. 2012:601018.

Park, H. -J., Shim, H. S., Ahn, Y. H., Kim, K. S., Park, K. J., Choi, W. K., Ha, H. -C., Kang, J. I., Kim, T. S., Yeo, I. H., Kim, J. S. \& Shim, I. 2012b. Tremella fuciformis enhances the neurite outgrowth of PC12 cells and restores trimethyltininduced impairment of memory in rats via activation of CREB transcription and cholinergic systems. Behav. Brain Res. 229:82-90.

Park, H. -J., Shim, H. S., Choi, W. K., Kim, K. S. \& Shim, I. 2011. Neuroprotective effect of Lucium chinense fruit on trimethyltin-induced learning and memory deficits in the rats. Exp. Neurobiol. 20:137-143.
Paxinos, G., Watson, C., Pennisi, M. \& Topple, A. 1985. Bregma, lambda and the interaural midpoint in stereotaxic surgery with rats of different sex, strain and weight. J. Neurosci. Methods 13:139-143.

Sala, C., Rudolph-Correia, S. \& Sheng, M. 2000. Developmentally regulated NMDA receptor-dependent dephosphorylation of cAMP response element-binding protein (CREB) in hippocampal neurons. J. Neurosci. 20:35293536.

Swartzwelder, H. S., Hepler, J., Holahan, W., King, S. E., Leverenz, H. A., Miller, P. A. \& Myers, R. D. 1982. Imparied maze performance in the rat caused by trimethyltin treatment: problem-solving deficits and perseveration. Neurobehav. Toxicol. Teratol. 4:169-176.

Thoenen, H. 1995. Neurotrophins and neuronal plasticity. Science 270:593-598.

Ueno, H. 2000. Enzymatic and structural aspects on glutamate decarboxylase. J. Mol. Catal. B Enzym. 10:67-79.

Walsh, T. J., Miller, D. B. \& Dyer, R. S. 1982. Trimethyltin, a selective limbic system neurotoxicant, impairs radialarm maze performance. Neurobehav. Toxicol. Teratol. 4:177-183.

Watanabe, M., Fuda, H., Jin, S., Sakurai, T., Hui, S. -P., Takeda, S., Watanabe, T., Koike, T. \& Chiba, H. 2012. A phenolic antioxidant from the Pacific oyster (Crassostrea gigas) inhibits oxidation of cultured human hepatocytes mediated by diphenyl-1-pyrenylphosphine. Food Chem. 134:2086-2089.

Woodruff, M. L., Baisden, R. H., Cannon, R. L., Kalbfleisch, J. \& Freeman, J. N. 3rd. 1994. Effects of trimethyltin on acquisition and reversal of a light-dark discrimination by rats. Physiol. Behav. 55:1055-1061.

Yokoyama, S., Hiramatsu, J. \& Hayakawa, K. 2002. Production of $\gamma$-aminobutyric acid from alcohol distillery lees by Lactobacillus brevis IFO-12005. J. Biosci. Bioeng. 93:9597.

Zhao, T. F., Xu, C. X., Li, Z. W., Xie, F., Zhao, Y. T., Wang, S. Q., Luo, C. H., Lu, R. S., Ni, G. L., Ku, Z. Q., Ni, Y. F., Qian, Q. \& Chen, X. Q. 1982. Effect of Tremella fuciformis Berk on acute radiation sickness in dogs (author's transl). Zhongguo Yi Xue Ke Xue Yuan Xue Bao 4:20-23. 